\title{
O passado revisitado: o Instituto de Malariologia e o Instituto de Endemias Rurais (INERu)
}

\author{
The past revisited: the Institute of Malariology and the \\ Institute of Rural Endemics
}

Ernest Paulini

Professor Emérito de Química Industrial da Escola de Engenharia da Universidade Federal de Minas Gerais Caixa Postal, 30140-970 Belo Horizonte - MG Brasil hpaulinyi@
PAULINI, E.: O passado revisitado: o Instituto de Malariologia e o Instituto de Endemias Rurais (INERu), apresentação de Gilberto Hochman.

História, Ciências, Saúde-Manguinhos, vol. 11(1): 143-58, jan.-abr. 2004.

Conferência do engenheiro químico dr. Ernest Paulini sobre sua trajetória profissional no campo da malariologia e da saúde pública, em particular sobre o Instituto de Malariologia, realizada no Centro de Pesquisas René Rachou, em 6.12.2002,

Belo Horizonte (MG).

PALAVRAS-CHAVE: malária, sal cloroquinado, Instituto Nacional de Endemias Rurais, esquistossomose.

PAULINI, E.: 'The past revisited: the Institute of Malariology and the Institute of Rural Endemics', presentation by Gilberto Hochman

História, Ciências, Saúde-Manguinhos,

vol. 11(1): 143-58, Jan.-Apr. 2004.

Conference presented by the chemical engineer Dr. Ernest Paulini on his professional history in the field of malariology and public health, focusing especially on the Institute of Malariology; beld at the Centro de Pesquisas René Rachou on 6 December 2002, in Belo Horizonte, Minas Gerais.

KEYWORDS: malaria, chloroquine phosphate, National Institute of Rural Endemics, schistosomiasis. 


\section{Apresentação}

A conferência que aqui reproduzimos apresenta-nos uma impecável trajetória profissional, que condensa e revela vários aspectos e dimensões da saúde pública brasileira das décadas de 1940 e 1950, em particular no campo da luta contra a malária e das instituições nela envolvidas. Nascido e graduado na Hungria, o dr. Ernest Paulini emigrou para o Brasil em 1948. Fez toda sua carreira profissional em instituições federais de saúde e na universidade pública, alcançando o título de Professor Catedrático de Química Industrial na Universidade Federal de Minas Gerais. Como engenheiro químico trabalhou no Instituto de Malariologia (IM), órgão de pesquisa do Serviço Nacional de Malária criado em 1946, inicialmente sediado em Duque de Caxias (RJ) e, em 1955, transferido para Belo Horizonte (MG). Em 1956, com a unificação dos serviços nacionais de combate às endemias no Departamento Nacional de Endemias Rurais (DNERu), o IM foi incorporado ao recémcriado Instituto Nacional de Endemias Rurais (INERu), órgão daquele departamento ao qual esteve vinculado o Centro de Pesquisas de Belo Horizonte (CBPH), que daria origem ao atual Centro de Pesquisas René Rachou.

Como chefe do Laboratório de Inseticidas de 1951 a 1970, depois denominado Laboratório de Química, o dr. Paulini participou ativamente, ao longo da década de 1950, de uma experiência fundamental, porém hoje esquecida, na saúde pública brasileira: o sal cloroquinado, ou 'método Pinotti', como ficou conhecido. Em tempos de Campanha Global de Erradicação da Malária, deslanchada pela Organização Mundial de Saúde (OMS) em 1955, a distribuição do sal de cozinha cloroquinado à população foi uma estratégia brasileira de superação de obstáculos aos métodos padronizados de luta contra a malária, como o uso do DDT e dos pesticidas, de efeito residual em regiões como a Amazônia. Em sua conferência, o dr. Paulini nos revela os bastidores dessa experiência, inclusive a tentativa de testá-la em países africanos e asiáticos sob os auspícios da OMS, da qual participou como consultor.

A história da saúde pública brasileira no pós-Segunda Guerra Mundial não obteve, até recentemente, a devida atenção por parte de historiadores e profissionais da saúde coletiva. Em particular, pouco se conhece e escreveu, do ponto de vista histórico, sobre os esforços brasileiros e internacionais, nas décadas de 1940 e 1950, para controle e erradicação de doenças como a malária, ainda hoje um dos principais problemas da agenda de saúde pública. Também pouco se escreveu sobre os profissionais que, não sendo médicos sanitaristas, tiveram importante participação na construção dos aparatos de saúde no Brasil contemporâneo. Essas foram décadas marcadas por um 'otimismo sanitário', em que se acreditava que os avanços da ciência, tais como os antibióticos, as vacinas e o DDT, poderiam derrotar definitivamente as doenças infectoparasitárias. Foi também uma época caracterizada pela ideologia do 
desenvolvimento, que balizou o debate sobre as relações entre combate às doenças e políticas de desenvolvimento econômico, bem como pelas grandes transformações em termos de institucionalização, profissionalização e especialização no campo da saúde pública.

O texto do dr. Ernest Paulini, além de ser uma agradável e instigante leitura, é uma contribuição para a compreensão histórica dos desafios da saúde pública brasileira.

Gilberto Hochman pesquisador da Casa de Oswaldo Cruz

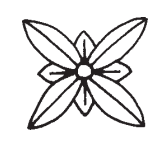

Q uero expressar os meus agradecimentos à prezada colega Virgínia Schall e à douta direção desta célebre instituição, pelo honroso convite para recordar e registrar para as gerações presentes um pouco dos primeiros passos de uma instituição jovem, chamada Instituto de Malariologia, no seio do Serviço Nacional de Malária.

Minhas anotações baseiam-se na convivência com esse centro de pesquisas e com a saúde pública por mais de vinte anos, durante os quais foi institucionalizado o combate aos flagelos da malária, doença de Chagas, filariose, leishmaniose, esquistossomose e do bócio endêmico. Essas recordações pessoais testemunham vários momentos da história da saúde pública, mais especificamente a projeção do Instituto no cenário nacional e internacional.

A característica daquela época era a de reconstrução, após cinco anos de guerra, destruição, ódio e miséria, situação que periodicamente se repete e nunca perde atualidade. O homem, mesmo em escala continental, usurpa egoísticamente privilégios e explora os fracos e miseráveis. Mesmo que eu não tivesse testemunhado a Grande Guerra, ainda assim censuraria esse tipo de conduta humana. Aplaudi quando, em resposta à demanda pacificadora, criou-se a Organização das Nações Unidas e a Organização Mundial de Saúde, com a intenção altamente humanista de impedir as freqüentes guerras entre países por meio de foros internacionais, discussão de problemas e situações históricas, planejamento de ações e oferecimento de auxílio aos países membros, atividade esta da qual eu mesmo participaria, mais tarde.

Nesse espírito de ajuda mútua e desenvolvimento nasceu também a Oficina Pan-americana de Saúde (OPAS). A instituição de pesquisa 
chamada Instituto de Malariologia, no município fluminense de Duque de Caxias, ao pé da serra, destacou-se por sua versatilidade, potencialidade e livre desenvolvimento. Tais condições resultaram em originalidade de projetos de pesquisa e solidez científica nos seus resultados.

Alguns anos mais tarde, em 1955, o Instituto foi transferido para Belo Horizonte, neste mesmo prédio em que hoje estamos recordando o passado para dar importância ao presente. Eram tempos de mudança, o Instituto de Malariologia expandiu-se para abraçar os problemas das endemias rurais e foi rebatizado como Instituto Nacional de Endemias Rurais. Outras reorganizações alteraram seu nome e, atualmente, a instituição denomina-se Centro de Pesquisas René Rachou, em homenagem a essa figura inesquecível, médico, pesquisador por excelência, colega e amigo fiel, que partiu tão cedo da nossa convivência, no ápice de sua carreira de sanitarista.

Com esse cabedal de lembranças, me encantou a oportunidade de falar de acontecimentos do passado para uma audiência na qual alguns talvez ainda não tivessem chegado a ver a luz do dia quando tais fatos ocorreram. Esta é uma situação curiosa, em que o palestrante tem vontade de descer virtualmente até a platéia para sentir as revelações escondidas sob o manto do cotidiano. Poder-se-ia dizer, também, que vou tentar abrir um álbum de fotos em preto-e-branco e substituir as imagens, uma a uma, por outras já coloridas.

Em defesa de minha narrativa começo a história 55 anos atrás, em Munique, na Alemanha, quando eu, então um jovem químico de origem húngara, fui entrevistado pelo dr. Almeida, chefe da Comissão Brasileira de Imigração e Repatriação e médico por formação. Foi ele quem me despertou interesse por este país-continente. Entre os itens rotineiros, ele perguntou-me, meio indiferente:

- Sua profissão?

— Engenheiro químico — respondi.

Ele levantou a cabeça e olhou-me com certa curiosidade:

- Tem especialização em alguma área?

— Em fabricação de inseticidas e combate aos insetos.

De repente, o dr. Almeida transformou-se numa pessoa jovial e amigável:

— Meu amigo, nós precisamos de você! Sabe que o maior inimigo do Brasil é a saúva? Com a sua ajuda poderemos convencer a natureza a ser mais amigável e produtiva.

Um colega estoniano, que ainda aguardava na fila de espera, observou:

- Você tem sorte! Reconheceram o seu valor e a sua profissão ganhou respeito.

Alguns meses mais tarde, em $1^{\circ}$ de maio de 1948, embarquei em Bremerhaven, junto com o dr. Almeida e centenas de brasileiros repatriados, com destino ao Rio de Janeiro. 
Os meses de adaptação ao novo ambiente e de aprendizagem da língua passaram rápida e despercebidamente, até que fui apresentado pelo dr. K.O. Courtney, representante da Fundação Rockefeller no Brasil, ao dr. Mário Pinotti, então diretor do Serviço Nacional de Malária no Rio de Janeiro. O tema da conversa, naturalmente, girava em torno do combate aos mosquitos, quando dr. Pinotti, demonstrando curiosidade, mudou de assunto:

— Qual é o produto inseticida que você está fabricando atualmente?

— Nenhum — foi a minha resposta —, a fábrica está produzindo corantes para a indústria têxtil.

O dr. Pinotti pareceu decepcionado:

— Lamento, nós não queremos pintar os anofelinos.

Repliquei com conviç̧ão:

— No mesmo equipamento em que fabrico corante, sintetizo também inseticida.

Um mês mais tarde, na Cidade dos Meninos, em Caxias, eu já estava utilizando a minha experiência, adquirida em Budapeste, na fabricação de BHC. O então recém-criado Instituto de Malariologia ocupava cerca de meia dúzia de casas, distantes cem metros uma da outra ao longo de uma estrada de barro. As casas foram projetadas e construídas por uma fundação filantrópica para abrigar meninos sem lar, mas foram cedidas ao Serviço Nacional de Malária para ser instalado ali o Instituto de Malariologia, um projeto prioritário.

A Seção de Química era chamada Laboratório de Inseticidas, mas lentamente ampliamos o escopo do laboratório para química geral, oferecendo orientação e ajuda aos colegas dos demais laboratórios: Ivan Ricciardi e Alina Perlowagora Szumlevitz, no Laboratório de Entomologia; Rostan Soares, na Parasitologia; e o engenheiro Luís Romeiro, então chefe do Instituto.

Serviços e problemas não faltaram. A grande 'vedete' no palco da saúde pública era o DDT, descoberto pelo químico suíço Paul Muller em 1939 e tido como potente inseticida. A substância química já havia sido descrita na literatura especializada em 1874, mas desconhecia-se sua grande utilidade para a agricultura e saúde pública. A sua baixa solubilidade aquosa evitou problemas de toxicidade para o homem e os animais domésticos, mas intoxicou e matou insetos e muitos invertebrados. Seu emprego foi decisivo em várias frentes, por exemplo nas operações militares durante a Segunda Grande Guerra, tanto no Pacífico quanto no Mediterrâneo, contra o mosquito da malária e, entre outros, contra o piolho-sugador. Na agricultura o DDT causava aumentos espetaculares de rendimento das safras, em conseqüência da dizimação dos insetos predadores.

O controle de qualidade do DDT e do BHC, utilizados pelo Serviço Nacional de Malária em todo o país, foi a principal e mais importante tarefa do nosso laboratório. Entretanto, apesar desse controle central de qualidade, surgiram dificuldades em algumas circunscrições do 
Serviço, devido a avarias durante o transporte e armazenamento e a problemas na aplicação domiciliar pelos guardas. Os problemas exigiam nossas visitas e, numa delas, estive pela primeira vez em Belo Horizonte.

Como aconteceu em outras ocasiões, a ordem de viagem dada pelo dr. Pinotti foi lacônica (porém suas instruções nunca eram ambíguas nem limitantes): "Favor dar assistência ao chefe da Circunscrição de Minas, dr. Olímpio de Silva Pinto." No dia seguinte, um DC-3 majestosamente ganhava altura e revelava aos curiosos passageiros, entre eles este conferencista, a beleza da Serra do Mar e os românticos "caminhos das minas" para as cidades de São João del Rei, Ouro Preto e a nova capital, Belo Horizonte.

O dr. Olímpio recebeu-me no aeroporto e, já no carro, me informou sobre seu problema, que aparentemente nada tinha a ver com a malária, mas com algo estratégico, político. Ele mostrou-me alguns jornais que noticiavam quase diariamente acidentes graves e mortais devido a picadas de escorpiões na cidade.

- O Serviço de Malária não tem obrigação de combater os escorpiões - comentei a notícia, reparando a superficialidade das reportagens.

- Certo - respondeu Olímpio - , mas o decreto presidencial vai demorar alguns meses e o prefeito me pediu ajuda, pois a prefeitura não tem inseticida nem guardas treinados. Além disso, a dedetização de Belo Horizonte poderá ser feita rapidamente por nossos guardas. E o mais importante dessa missão é que ela nos trará um benefício invisível: o sucesso da eliminação dos focos de escorpiões será comentado em todo o estado, pois a maioria dos belo-horizontinos tem família no interior, e minhas equipes de dedetização domiciliar receberão todo o apoio no interior, após a vitória sobre os escorpiões.

Eu estava sendo apresentado à mola-mestra do trabalho das equipes das campanhas de saúde pública: o relacionamento atencioso e pessoal com a população. Em 24 horas traçamos o plano de ação, e em uma semana todos os focos conhecidos foram banhados em inseticida. A população aprendeu a lição e o esquema foi repetido com sucesso, por muitos anos.

Esse pequeno exemplo revela modificações profundas na percepção de saúde pública, tanto por parte das autoridades sanitárias quanto por parte da população, que descobriu nos inseticidas uma arma poderosa de controle. Foi uma demonstração convincente e gratificante.

Para nós, a literatura científica da época estava repleta de estudos relatando a toxicidade dos inseticidas conhecidos contra os mais variados tipos de insetos e procurando revelar, entre outros pontos obscuros, seu modo de ação, sua permanência e sua toxicidade ao meio ambiente. Os laboratórios das grandes firmas químicas, por sua vez, sintetizavam e testavam anualmente milhares de compostos orgânicos para competir com o DDT e o BHC.

O Laboratório de Inseticidas do Instituto Nacional de Malária não foi um simples observador dessas atividades. Além dos melhoramentos 
tecnológicos efetuados na aplicação de inseticidas no campo, colaboramos com o Laboratório de Entomologia nos ensaios biológicos e desenvolvemos técnicas padronizadas para acompanhar a susceptibilidade dos insetos de importância médica — especificamente anofelinos, culicíneos e triatomíneos - aos inseticidas empregados no país. Como reconhecimento desses esforços representamos o país em reuniões de peritos da Organização Mundial de Saúde e participamos de vários estudos internacionais, com novos inseticidas mais ativos e menos tóxicos.

Naquele período ocorreu a mais memorável visita ao nosso laboratório, a do dr. Paul Muller, prêmio Nobel de Química. Ele percebeu um modelo tridimensional da estrutura do DDT sobre minha mesa e interessou-se por minha pesquisa. Falei-lhe que gostaria de descobrir por que somente um, dos muitos derivados do DDT, possui valor como inseticida. Ele acompanhou com atenção a minha exposição e estimuloume a investigar sobre a resposta, que foi apresentada num congresso de química no Rio de Janeiro.

Os resultados excelentes observados na eliminação dos anofelinos vetores, em alguns estados brasileiros e em vários países da Europa e das Américas, fizeram supor a sua erradicação em áreas continentais, inclusive no Brasil. A expansão da dedetização domiciliar foi limitada apenas por problemas de organização e orçamento, mas permanecia sem resposta uma importante pergunta: o que fazer na Amazônia, onde os vetores da malária entravam e saíam livremente das choças evitando, assim, qualquer contato com os inseticidas depositados no sapé? Com este argumento, o dr. Rachou foi um dos poucos malariologistas que consideraram a erradicação da malária no Brasil 'parcialmente' viável.

Idéias, com ou sem brain-storming, nunca nos faltavam no Instituto, e sempre surgia algo novo na elaboração dos planos detalhados, em face da ampla variedade de comportamento dos diversos mosquitos vetores da malária e da filariose. As reuniões dos coordenadores do Serviço de Malária com o diretor Pinotti eram caracterizadas pela informalidade. Os grupos, instalados numa sala espaçosa, trocavam idéias, notícias e informações. Pinotti, entre um e outro telefonema, circulava pela sala apresentando aos grupos os problemas do dia e deixando-os discutirem entre si as alternativas, livres de pressão e constrangimentos.

Certo dia Pinotti aproximou-se de nosso grupo e declarou:

- O combate aos anofelinos com DDT na selva amazônica é deficiente, como Rachou tinha demonstrado, porque os mosquitos escapam do inseticida. Temos duas alternativas: a primeira seria um repelente de longa duração, que ainda está por ser inventado; a segunda poderia ser a distribuição periódica de droga antimalárica. Pensem nisso!

E, sem esperar resposta, passou para o grupo ao lado. Meus dois companheiros de grupo tinham chefiado circunscrições do Nordeste e 
demonstravam pouco interesse por repelentes ou insetífugos, mas cada um comentou as dificuldades de detectar e tratar casos agudos de malária nas populações rurais. A conversa - estimulada pelo cafezinho servido de trinta em trinta minutos, cuja fama foi largamente comentada no Rio de Janeiro como o café mais gostoso da cidade - foi interrompida pela nova chegada do diretor, que então me dirigiu a pergunta:

— Então, chegaram a alguma proposta?

Houve um momento de silêncio, quebrado repentinamente pelo meu sotaque húngaro:

- Senhor diretor, o desenvolvimento de um repelente de longa duração pode demorar não meses mas anos, portanto não é idéia a ser considerada num projeto de grande projeção como o nosso, o de erradicação da malária. A segunda alternativa, distribuição de antimaláricos pelos guardas de campo, parece mais viável. Os colegas aqui me informaram a respeito das dificuldades observadas nas suas respectivas circunscrições, e pode-se prever que a distribuição de antimaláricos pelos guardas do Serviço Nacional da Malária na Amazônia será muito onerosa. Seria mais racional seguir a metodologia da campanha contra o bócio endêmico, em que quantidades mínimas de iodato são misturadas com o sal de cozinha comercializado para a população humana, nas áreas afetadas.

- Mas cloroquina não é iodato - interrompeu-me o nosso diretor.

- Sim, por isso o primeiro passo deve ser o de investigarmos a resistência da cloroquina ao seu cozimento com alimentos, em condições reais.

Dois dias depois o chefe de gabinete telefonou-me, comunicando que o dr. Pinotti gostaria de ver o resultado sobre a estabilidade da cloroquina. Ele, Pinotti, não costumava esperar vários dias para receber informações ou soluções relativas a problemas que considerava importantes. Freqüentemente eu saía do seu escritório diretamente para o aeroporto. Dessa vez a sua chamada foi o sinal de largada do Projeto do Sal Cloroquinado, que durou dez anos e resultou em muito trabalho inovador e muitas publicações, tanto no Brasil como no exterior.

A participação dos pesquisadores do Instituto de Malariologia no Congresso da Sociedade Brasileira de Higiene de 1952, portanto há cinqüenta anos, prometia ser uma ocasião muito especial. Minha surpresa foi o comportamento dos colegas do IM, que começaram a falar apaixonadamente sobre os trabalhos que iriam apresentar e me perguntaram o que eu estava preparando. O entusiasmo foi contagiante. Como resultado, o $10^{\circ}$ Congresso Brasileiro de Higiene, realizado em Belo Horizonte em outubro de 1952, tornou-se a mais freqüentada e a mais produtiva reunião científica ocorrida até então, com cerca de quinhentos inscritos e aproximadamente trezentos trabalhos apresentados. O presidente de honra do congresso foi Juscelino Kubitschek, então governador de Minas Gerais. Participaram do 
congresso várias personalidades internacionais, dentre elas dr. Arnaldo Gabaldón, da Venezuela; dr. Carlos Alvarado, da Argentina, que mais tarde foi meu chefe na Organização Mundial de Saúde, em Genebra; e dr. Cecil Hackett, diretor do Wellcome Museum of Medical Sciences.

O temário do congresso foi abrangente, começando com o tema do planejamento e da administração dos serviços médico-sanitários. Outro grupo discutiu os problemas de nutrição: a avitaminose, a carência protéica e o bócio endêmico. O tema mais extenso foi o da epidemiologia e profilaxia de doenças transmissíveis, que incluía trabalhos sobre esquistossomose, malária, doença de Chagas, leishmaniose tegumentar, filariose, peste e febre maculosa, juntamente com a biologia e distribuição geográfica dos mosquitos e o emprego de inseticidas e bromelicidas.

Na sessão sobre malária, apresentei minha investigação sobre a estabilidade da droga antimalárica cloroquina, que, misturada ao sal de cozinha e submetida a cozimento, permanecia quimicamente inalterada, podendo ser misturada aos alimentos como medida de controle da parasitose. O trabalho despertou grande interesse entre os congressistas e estimulou a continuação das pesquisas, a partir de então em maior amplitude.

Voltando ao hotel para almoçar, o grupo continuou a conversa animada sobre as idéias levantadas durante a sessão, enquanto os garçons distribuíam alfaces frescas como acompanhamento do prato principal. O colega sentado em frente a mim já havia cortado o seu filé, quando percebi algo estranho na salada. Mantendo o tom alegre, comentamos:

- Você foi privilegiado, pois recebeu uma porção adicional de carne com a sua salada.

Ele, curioso, virou a folha e encontrou um planorbídeo bem desenvolvido, tentando esconder-se em sua concha e proteger-se contra a hostilidade do ambiente. O garçom, embaraçado, retirou rapidamente o prato, embora alguém entre nós lamentasse:

- Perdemos uma grande oportunidade de levar ao plenário do congresso um planorbídeo coletado na Praça Sete. E talvez infectado por Schistosoma mansoni?

Mesmo sem aquele planorbídeo, o congresso representou um marco na evolução qualitativa e quantitativa do controle de doenças transmissíveis no país.

No Instituto de Malariologia, a carga de trabalho aumentou com a modificação do regimento do Serviço Nacional de Malária, que passava a ser incumbido de organizar e realizar, em todo o país, os planos de combate à filariose e ao escorpionismo. O decreto com o novo regimento entrou em vigor em setembro de 1952.

A falta de pessoal nos laboratórios para o cumprimento das novas atribuições foi contornada, pelo dr. Pinotti, com a contratação de toda 
a turma de recém-diplomados da Escola de Farmácia de Outro Preto, entre eles José Pedro Pereira, que todos aqui conhecem. Ele foi meu fiel e eficiente colaborador durante vinte anos. Outro membro desse grupo foi Geraldo Chaia, do Laboratório de Esquistossomose.

Os anos seguintes foram agitados. O dr. Pinotti assumiu a pasta ministerial em 1954, para diretor do Serviço Nacional de Malária foi nomeado o professor Manuel J. Ferreira e para a chefia do Instituto de Malariologia, o dr. René G. Rachou.

Circulavam rumores sobre a mudança do Instituto, que confirmei quando me enviaram a Belo Horizonte com a incumbência de verificar a viabilidade da transferência dos laboratórios da Cidade dos Meninos, no Rio de Janeiro, para o prédio em que a instituição funciona até hoje, na capital mineira. Confesso que meu parecer favorável à mudança foi amplamente influenciado pelo ambiente ameno da cidade, pela cordialidade dos seus habitantes, pelos colegas amigáveis que cheguei a conhecer em minhas freqüentes visitas oficiais. Assim ocorreu, quase naturalmente, que minha família foi a primeira do Instituto a embarcar, junto com René Rachou, definitivamente para Belo Horizonte, e esta cidade tornou-se o nosso 'ancoradouro'. Esta palavra daria título à biografia de minha família, escrita em forma romanceada e publicada posteriormente pela minha esposa Lívia, em 1981.

A transferência do Instituto de Malariologia para Minas Gerais provocou mudanças profundas no pessoal e no ambiente de trabalho. Muitos servidores tinham suas vidas enraizadas no Rio de Janeiro. Para que os projetos de pesquisa em andamento não sofressem descontinuidade, Rachou teve de preencher as vagas criadas pelos cariocas que não se transferiram. Os professores Amílcar Viana Martins, José Pellegrino, Zigman Brenner, Lobato Paraense, Giorgio Schreiber, Marcelo Vasconcelos Coelho e Naftale Katz, entre outros, formaram, durante os anos seguintes, a galeria de eminentes pesquisadores que continuaram a projetar o alto conceito desta instituição além das fronteiras nacionais.

As pesquisas com o sal antimalárico continuavam, já em escala comunitária. Por sugestão de Fernando de Bustamante, chefe do Programa de Erradicação da Malária, foi escolhida a área de Engenheiro Dolabela, no município de Bocaiúva (MG), para os ensaios de campo. Naquele tempo, a viagem, feita de jipe, de Belo Horizonte até a localidade levava seis horas na época da seca e oito, na época da chuva. A fazenda, com uma fábrica de açúcar e álcool e uma população de oito mil pessoas, apresentou condições favoráveis para a pesquisa. Após dois anos de atividade na área, os casos agudos desapareceram e reduziu-se para quase zero o índice de positividade, nos ensaios hematológicos.

Um ano depois do término do nosso trabalho, dirigi uma carta ao engenheiro superintendente da fazenda indagando se foi observada, durante a aplicação do sal cloroquinado, diferença na produtividade 
dos trabalhadores rurais, em especial os cortadores de cana, comparativamente aos anos anteriores. A resposta foi categórica: a produção média dos cortadores de cana, nos anos anteriores ao uso do sal cloroquinado, era de $900 \mathrm{~kg} / \mathrm{dia} /$ pessoa. Durante os dois anos de distribuição de sal cloroquinado, a produtividade alcançou $1.500-1.600 \mathrm{~kg} /$ dia/pessoa. O superintendente salientou, na carta, que não houve nenhuma modificação no sistema nem nos equipamentos de corte, e o bom resultado só podia ser atribuído ao melhor estado de saúde dos trabalhadores.

$\mathrm{Na}$ época os economistas começavam a questionar os programas e as despesas de saúde pública, especialmente os planos de erradicação da malária, com perguntas tais como: "Quantos dias/horas de trabalho são perdidos mensal ou anualmente devido à malária?" "Pode-se quantificar a diminuição do rendimento de trabalho, seja manual ou mental, atribuída a um parasitismo crônico?" As respostas a essas indagações foram relativamente acessíveis em áreas malarígenas, como demonstrou a citada carta do superintendente de Engenheiro Dolabela, mas tornaram-se muito complicadas nos estudos referentes à esquistossomose. Recordo-me de uma publicação americana que relatou a pesquisa a esse respeito, realizada numa ilha da América Central que apresentava esquistossomose endêmica. Os autores chegaram à conclusão de que era impossível quantificar a produtividade individual, fosse na pessoa portadora ou na não-portadora do parasito, porque os trabalhadores atuavam em grupos, em que os mais fortes compensavam a debilidade dos demais.

No que diz respeito à esquistossomose, Toshie Camei Kawano e Cecília Pereira de Souza trabalharam em nosso laboratório, com grande eficiência, no combate aos planorbídeos hospedeiros do Schistosoma mansoni, testando centenas de produtos químicos promissores e descobrindo dezenas de fatores ambientais que poderiam reduzir a eficácia das medidas preventivas. Na área de controle biológico dos planorbídeos, Helen Paulini, minha filha, conseguiu resultados promissores demonstrando a dominância do caramujo Pomacea sobre a Biomphalaria, no mesmo criadouro. A demonstração no campo ocorreu na área da Pampulha, com o desaparecimento do B. glabrata em numerosos criadouros. Seu trabalho foi publicado no Boletim da OMS, em 1972, e coroado com uma bolsa de estudos no Instituto de Medicina Tropical de Lisboa, oferecida pelo então diretor daquele órgão, professor Fraga de Azevedo.

Os ensaios de campo com o sal cloroquinado aumentaram. As experiências realizadas no estado do Pará, ao longo do rio Cupim, e em Santa Catarina, na ilha de São Francisco, foram confirmatórias.

Em agosto de 1959, o dr. Pinotti surpreendeu-me com a seguinte notícia:

- A Organização Mundial de Saúde pretende experimentar o sal cloroquinado em três países diferentes: Gana, na África; Camboja, 
na Ásia; e Nova Guiné, no Oceano Pacífico. O senhor aceitaria se eu o indicasse para organizar esses ensaios?

Durante uma fração de segundo, passaram pela minha memória as peripécias na Amazônia com o dr. Scaff, no rio Capim, onde caçávamos galos selvagens para o jantar, e as exaustivas viagens de jipe entre Belo Horizonte e Engenheiro Dolabela. "Que aventura!", pensei, e... aceitei.

Minha premonição tornou-se realidade. Foi mesmo uma aventura, a começar com as semanas ocupadas com preparativos burocráticos licenças, substituições, programas de viagens, passagens, contatos exames de saúde, vacinação e provisão de medicamentos. No fim de setembro embarquei para a Súça, de onde retornaria em março do ano seguinte.

Genebra é famosa no mundo inteiro não somente por seus relógios, mas também pelos súditos do relógio. No Palácio da Organização Mundial de Saúde era preciso combinar, por telefone, o dia, a hora e o minuto da visita, além de sua duração. Nem um minuto de atraso na chegada ou na saída era tolerado. A servidão imposta pelo relógio era revogada aos sábados, com muita alegria, na tradicional feijoada oferecida aos compatriotas brasileiros pelo dr. Marcolino Candau, diretor geral da OMS, que por vinte anos (1953-1973) presidiu essa instituição internacional, a mais respeitada do mundo.

Na Divisão de Malária, chefiada pelo dr. Carlos Alvorado, fui recebido com muita cordialidade, assim como ocorrera no nosso encontro no $10^{\circ}$ Congresso Brasileiro de Higiene, em Belo Horizonte. Com a sua orientação e com a ajuda do seu colaborador, dr. Bruce-Chwatt, consegui organizar meu itinerário e cronograma para cinco meses de estada. O sexto e último mês foi reservado para redigir meu relatório final em Genebra, cujas propostas foram mais tarde confirmadas nos países visitados.

Cinco meses, ou seja, 150 dias viajando, observando e conversando resultaram em muitas impressões, informações e sentimentos. Gostaria de citar apenas alguns deles, gravados entre as minhas reminiscências, para ilustrar minha exposição. (As muitas outras visitas internacionais que fiz, como as de Porto Rico, Guadalupe, Santa Lucia e Suriname, serão publicadas no meu livro em preparação, intitulado Mabubay.)

Minha primeira parada foi Manila, capital das Filipinas. Era uma viagem aérea de 27 horas num DC7, um preparo físico e mental para a atividade que estava por vir - trabalhar na escala primordial extrema da raça humana, com o objetivo de ajudar os menos favorecidos. Eu guardava uma certa desconfiança de que os governantes contemplados com o nosso projeto privilegiariam alguns grupos e nos esconderiam as populações mais primitivas, porém a minha missão era decididamente técnica e não política. Eu visitaria as áreas escolhidas, discutiria com as autoridades locais os planos de preparo, transporte e realização de levantamentos epidemiológicos, de distribuição de sal e eventuais 
dificuldades. Mas uma curiosa pergunta ficava sempre no ar: eu vigiava a equipe, ou era eu o vigiado?

Depois segui para Port-Moresby, capital da então Nova Guiné inglesa, onde tomei parte num Congresso Internacional de Malária, cujos participantes estavam interessados em implantar o Projeto do Sal Cloroquinado naquela região

A outra extremidade da ilha de Nova Guiné, naquele tempo, era protetorado da Holanda. Descendo do avião na cidade de Holandia hoje Djajapura, pertencente à Indonésia —, uma pequena comitiva veio ao meu encontro mostrando grande entusiasmo em me receber. Depois das formalidades, perguntei ao jovem médico Meuwissen:

- Por que toda essa ovação?

-É a nossa alegria, doutor, pois lendo os seus trabalhos esperávamos um pesquisador barbudo e velho, que não agüentaria nem 24 horas no mato.

Passamos 15 dias na selva tropical, caminhando em trilhas lamacentas e visitando uma dúzia de vilarejos, na companhia de dois médicos holandeses, quatro carregadores de mantimentos e malas e dois policiais armados, um dos quais servia como intérprete para os nativos. Comentava-se que, na década de 1940, foram os soldados japoneses quem estabeleceram contato permanente com os nativos da selva, antropófagos. Por isso a presença dos policiais armados em nossa expedição. Eles foram nossos guias, comandaram nossos descansos, colheram e apreciaram conosco as frutas tropicais da floresta. A convivência desenvolveu afinidades entre os colegas e demais membros da equipe, e éramos capazes de rir quando contávamos o número de sanguessugas em nossas botas, a cada parada.

Na última aldeia visitada encontramos um missionário franciscano holandês, que vivia lá havia anos e que, com a ajuda dos indígenas, tinha aberto e mantinha uma pequena clareira no mato, do tamanho de um campo de futebol, para pouso e decolagem de aviões. Durante o jantar o padre João comentou as freqüentes chuvas da época e disse:

- Vamos rezar para que não chova pela manhã e o avião anunciado possa aterrizar.

A prece funcionou e voltamos sãos e salvos a Holandia. Seis meses mais tarde, já em Belo Horizonte, recebi uma carta do padre, por intermédio da Organização Mundial de Saúde, felicitando-me pela sorte em ter conseguido sair da selva, pois nos cinco meses seguintes os aviões não aterrissaram, devido ao mau tempo. Ele próprio ficara sem contato com o mundo, porque até as baterias de seu rádio se esgotaram. Foi naquela época, também, que um jovem membro da família Rockefeller desapareceu nas traiçoeiras águas da Nova Guiné.

Mais tarde recebi a tese de doutoramento, pela Universidade Leiden, de Jupp Meuwissen, mais precisamente Josephus Hilarius Edmundus Thomas Meuwissen, um dos companheiros de andanças pelas matas de Nova Guiné. No relato de seus primorosos trabalhos, ele registrava 
algumas conclusões contundentes: i) a elevada resistência dos plasmódios locais à droga antimalárica pirimetamina; ii) o funcionamento normal e eficiente da cloroquina; iii) a desproteção das crianças do grupo etário de zero a três anos que não receberam, na alimentação, o sal antimalárico. E indicava essas imperfeições na seguinte citação: "Freqüentemente se observa que o maior obstáculo na erradicação da malária é o próprio homem."

Encontrei-me com Meuwissen 15 anos mais tarde, na Holanda. Já professor, lutava ainda contra os parasitos da malária, tentando desenvolver uma vacina contra eles, mas guardou o seu fino humor da juventude:

- Meu caro amigo! Lembra-se do que nós cantávamos na floresta, indo para Waris?

— Sim — respondi —, foi o cenário mais esquisito para as melodias imortais de Verdi.

Ele respondeu:

— Temos de admitir que os paradoxos são os melhores estimulantes na vida.

Durante minhas andanças encontrei muitos cientistas espirituosos como Jupp Meuwissen, que coloriram as minhas anotações.

O segundo campo experimental do sal cloroquinado foi Camboja. Mal cheguei em Phnom Penh e me instalei no hotel, recebi um convite para a noite de gala que o príncipe Shihanuk oferecia às personalidades internacionais que se encontravam na cidade. No evento, um médico francês sentou-se ao meu lado e, movido pela semelhança das nossas atividades e experiências, comentou a sua vida em Laos, país vizinho do Camboja, de onde ele chegara havia pouco dias. "Em Laos tudo é tranqüilo como aqui, embora tenha as suas peculiaridades" - disse ele, enquanto acompanhávamos o balé das dançarinas reais em suas vestes exóticas e a música estranha aos ouvidos ocidentais.

Na minha carta para a família comentei a pacificidade do ambiente e do povo cambojano, avaliando que ali a revolução chinesa não chegaria, e os planos de saúde sobre a malária estariam garantidos. O tempo mostrou que, embora eu fosse aprovado com louvor nos trabalhos científicos, fui reprovado definitivamente no teste de profecia: dois anos mais tarde Vietnã, Laos e Camboja tornaram-se sangrentos satélites da China. A violência venceu a saúde pública e seu conteúdo moral, a fraternidade. A saúde dos povos foi relegada ao último lugar.

Gana foi o terceiro e último campo experimental do sal cloroquinado. Paisagens escondendo ferro, ouro e diamantes, semelhantes às de Minas Gerais, envolviam a beira-mar; em perfeita conservação, o romântico castelo e o forte de Elmina, a ostentar sua data de nascimento, 1482, em azulejo português.

A duzentos quilômetros do litoral, ao norte, começava a região semi-árida, com suas dezenas de tribos e milhares de reservatórios de água para os períodos de seca. Os poços estavam superpovoados por 
crocodilos, nos quais, pela crença do povo, continuavam vivas as almas dos antepassados. Os répteis não nos atacaram quando os fotografei de perto. Aparentemente estabeleceu-se um apreço silencioso entre eles e nós: de um lado a lentidão; do outro, a vivacidade — tal como a comunidade local versus o visitante estrangeiro.

Nas feiras semanais dos vilarejos ocorriam as trocas de objetos e mercadorias, como o sal, que era monopólio de uma tribo distante. O chefe dos salineiros, como bom vendedor, disse-me:

- O seu sal do mar dá dor de barriga; o meu sal, nunca!

Os curandeiros formavam outra ala de resistência. Um deles mandoume, pelo intérprete, o seguinte recado: "O meu deus é mais forte que o seu." Tais pronunciamentos indicavam claramente a ausência de racionalidade, reforçada por uma atitude autoritária. Entretanto as autoridades locais nos deram suas boas-vindas e asseguraram a realização das nossas instruções. Por fim, o deus ganense provou ser mais forte.

Depois de ter voltado do exterior, comecei a dar conferências sobre minhas impressões, que mais pareciam uma seqüência de aventuras intercaladas por trabalhos científicos, devido à interferência de inúmeros fatores desconhecidos e situações imprevisíveis. Intitulei essas palestras de 'A volta ao mundo com um microscópio'. Na verdade, se eu tivesse um microscópio na bagagem durante as minhas viagens, o instrumento dificilmente teria chegado são e salvo a Belo Horizonte. Perto de Bolgatanga, no norte de Gana, numa parada do jipe para descanso, uma família de chimpanzés interessou-se, e muito, por nossas malas.

Todas essas viagens me revelaram a grande variedade de condições de vida dos povos que visitei e sua capacidade de vencer empecilhos, como secas, inundações e catástrofes de toda natureza. Essas características das tribos, juntamente com a tradição, que é o repositório do saber e deveres coletivos, representam a força da sobrevivência e moldagem das gerações. A diferenciação entre grupos humanos pode ter ocorrido em virtude da vitalidade de cada povo, de seu ambiente mais amplo e da influência de seus líderes, que convenciam a coletividade a seguir seus sonhos e aspirações. Admitindo essa possibilidade, pode-se realizar, em retrospecto, algumas interpretações interessantes para as situações imprevisíveis que ocorrem entre grupos humanos e consultores da OMS.

A OMS, com seu pessoal de alta categoria, concentra seu empenho na saúde global dos povos, visando o crescimento de todos. A campanha mundial Pólio Plus, apoiada pelo Rotary Internacional, é um exemplo singular dessa filosofia altamente significativa, que se ajusta sem dificuldade aos ideais humanitários.

Creio que os cientistas consultores, assim como nós, não querem interferir no crescimento de qualquer fase sadia da vida dos povos. As diferenças observadas surgem como 'atitudes estranhas' diante de uma situação complexa, desconhecida. Os pesquisadores, desde Descartes, abordam um problema partindo de um ponto supostamente 
estabelecido e lógico e procuram identificar tantas etapas quantas sejam necessárias para chegar ao resultado desejado. Uma população menos sofisticada não enfrenta um problema como se fosse resolvível; e, sem qualquer tentativa para saná-lo, recai na atitude defensiva, costumeira, que está mais ao seu alcance imediato. Chegase, assim, à conclusão de que a idéia de saúde global deve ser abrangente e claramente destinada à humanidade, para que possa ser assimilada por cada sociedade-alvo e todos sejam beneficiados. Conseqüentemente, é nosso dever semear ideais de vida, moral, costumes e boa vontade, objetivando a realização de uma vida saudável, feliz e gloriosa, mesmo quando essa meta existe somente na imaginação.

Obrigado pela atenção. 